\title{
LEVELS AND WATER SOLUBLE ORGANIC CARBON OF ATMOSPHERIC NANOPARTICLES IN A LOCATION OF HA NOI, VIET NAM
}

\author{
Nguyen Thi Thu Thuy ${ }^{1,2}$, Nghiem Trung Dung ${ }^{1, *}$, Kazuhiko Sekiguchi $^{3}$, \\ Ryosuke Yamaguchi ${ }^{3}$, Ly Bich Thuy ${ }^{1}$, Nguyen Thi Thu Hien ${ }^{1}$ \\ ${ }^{1}$ School of Environmental Science and Technology, Hanoi University of Science and Technology, \\ 1 Dai Co Viet, Ha Noi, Viet Nam \\ ${ }^{2}$ Faculty of International Training, Thai Nguyen University of Technology, 3/2 Road, \\ Thai Nguyen, Viet Nam \\ ${ }^{3}$ Graduate School of Science and Engineering, Saitama University, \\ 225 Shimo-Okubo Sakura, Saitama, Japan \\ "Email: dung.nghiemtrung@hust.edu.vn
}

Received: 10 April 2017; Accepted for publication: 16 June 2017

\begin{abstract}
Atmospheric nanoparticles $\left(\mathrm{NPs}\right.$ or $\left.\mathrm{PM}_{0.1}\right)$ were investigated at a site inside the campus of Hanoi University of Science and Technology (HUST) in Hanoi, Viet Nam. The sampling was conducted during a rainy season (August, 2015) and a dry season (October to December, 2015). Mass was weighed by an electronic micro-balance, Sartorius ME2, $10^{-6} \mathrm{~g}$. Number concentrations were measured by an electrical mobility spectrometer (NanoScan, SMPS TSI Model 3910). Water soluble organic carbon (WSOC) was analyzed by a total carbon analyzer (TOC-V $\mathrm{V}_{\mathrm{CHP}}$, Shimazu). The correlations between WSOC and other components were studied to primarily identify the sources of atmospheric nanoparticles. Secondary organic carbon (SOA) was estimated using elemental carbon (EC) - tracer method. Selected characteristics of nanoparticles including mass concentrations, number concentrations, and WSOC were determined.
\end{abstract}

Keywords: nanoparticles, mass concentration, number concentration, WSOC, SOA, Ha Noi.

\section{INTRODUCTION}

Recently, the scientific community has high concern about nanoparticles (NPs), which are considered to give probably adverse impacts on human health [1], visibility and climate change [2]. Such negative impacts could be attributed by: (i) a tiny size that can penetrate deeply and accumulate in the organs of our bodies, (ii) a very high number concentration, and (iii) a greater specific surface area that can be bounded by toxic compounds. Therefore, it is important to gain the best understanding about the species' concentrations of NPs to assess these effects. 
Organic carbon (OC) is one of the most dominant components of atmospheric nanoparticles, representing $30-73 \%$ of the total mass concentration [3, 4]. Organic aerosols either can be emitted to the atmosphere as primary organic ones or are formed in the atmosphere through gas-to-particle conversion processes (secondary organic aerosols - SOA). While it is complicated to estimate directly the level of SOA, water soluble organic carbon (WSOC) can be used as an indicator of the formation of SOA because SOA compounds contain polar functional groups (e.g. hydroxyl, carbonyl, and carboxyl) [5] that attribute to the water-soluble characteristics of SOA. Although WSOC can come from primary sources such as motor vehicles, fossil fuel combustion, and biomass burning, WSOC has been used as a tracer for SOA because the major fraction of SOA is associated with WSOC. In addition to its potential as a general tracer for biomass burning emission and SOA, WSOC may influence regional climate [6] and human health [7]. For these reasons, it is important to get the comprehensive knowledge about WSOC.

Most previous studies of WSOC have generally focused more strongly on suspended particulate matter (TSP), $\mathrm{PM}_{10}$ and, more recently, on $\mathrm{PM}_{2.5}$ [5, 6]. The investigations on WSOC of nanoparticles are very few, especially in developing countries. To the best of our knowledge, publications conducted in Viet Nam on NPs, the higher potential particles to human health and environment, are very scarce [8 - 10]. Moreover, no data on WSOC of NPs in the country are available in the open literature. To fill the data gap in mass concentration, number concentration, and WSOC of NPs in this region, this study is, therefore, aimed at: (i) the determination both mass and number concentrations of NPs, (ii) the determination of the characteristics of atmospheric WSOC in NPs in Viet Nam, in which the relationships between WSOC and other carbonaceous components will be analyzed deeply. These relationships would be valuable to examine the possible emission sources of NPs in the atmosphere.

\section{MATERIALS AND METHODS}

\subsection{Study area}

Ha Noi, located in the Red River delta in the North Viet Nam (21.021N, 105.851E), about $100 \mathrm{~km}$ west of the East Sea, is the capital of Viet Nam and the second largest city in the country. Ha Noi has a tropical monsoon climate with two monsoon seasons. The area is under the influence of northeast monsoon during winter while being under the influence of southeast monsoon during summer. From October to December, continental air masses flow coming from the inland of China brings dry and cold air. From January to March/ April, maritime airflow traveling a long way over the Pacific Ocean brings warm, humid and better dispersion conditions. In summer, air masses coming from the Highs over the Indian Ocean and the subtropical High over the East Sea bring moist air and monsoon rains. However, heavy rains mainly occur in July and August in association with tropical depressions. The mean annual rainfall in Ha Noi is $1800 \mathrm{~mm}, 80 \%$ of which are recorded from May to September [11].

In order to investigate the characteristics of NPs in Ha Noi, a sampling site located at the $3^{\text {rd }}$ floor of the Center of Foreign Languages, Ha Noi University of Science and Technology (HUST) $\left(21^{\circ} 00.17 \mathrm{~N}\right.$ and $\left.105^{\circ} 50.37 \mathrm{E}\right)$ was chosen (Figure 1). This sampling site can be considered as a mixed site affected by several activities including transportation, construction, domestic cooking, and laboratory etc. All those sources can contribute to the levels and compositions of NPs. 
Sampling was conducted during the wet season and the dry season. These sampling periods were selected so that the influence of seasonal reversing winds with temperature and relative humidity characteristics corresponding to the seasons in Ha Noi, Viet Nam, could be observed.

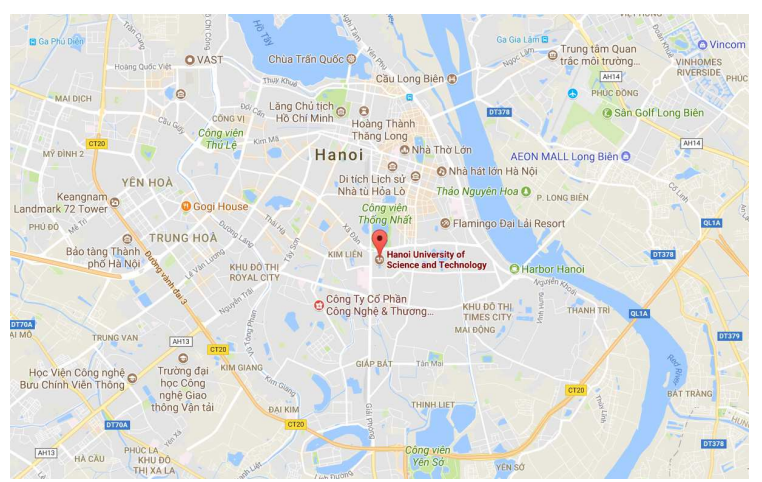

Figure 1. Location of sampling site in Ha Noi.

\subsection{Sampling and analytical method}

An inertial fibrous filter (INF) sampler (the newest version KU - TSC 26A57C1, Kanazawa University) with a design airflow of $40.0 \mathrm{~L} / \mathrm{min}$ was used to collect NPs. The INF sampler consists of four impaction stages that collect particles with equivalent diameters of 10 , 2.5, 1.0, and $0.5 \mu \mathrm{m}$. The system also has one inertial filtration stage composed of unwoven stainless steel fibers for collecting particles larger than $0.1 \mu \mathrm{m}$ after the four impaction stages. NPs are collected uniform on to a $55 \mathrm{~mm}$ quartz fiber filter (2500 QAT - UP, Pallflex, CT, USA).

The 24-h sampling duration was conducted in August (rainy season) and from October to December (dry season) of 2015. Seventeen samples and 3 blank samples were collected for the rainy season; and 28 samples and 7 blank samples were collected for the dry season, respectively. Flow rates of the sampler and meteorological parameters, including wind direction and velocity, temperature and humidity, were measured every hour during sampling. Some meteorological data are shown in Table 1.

Table 1. Meteorological data.

\begin{tabular}{cccccc}
\hline & $\begin{array}{c}\text { Average } \\
\text { temperature } \\
\left({ }^{\circ} \mathrm{C}\right)\end{array}$ & $\begin{array}{c}\text { Average } \\
\text { relative } \\
\text { humidity }(\%)\end{array}$ & $\begin{array}{c}\text { Average wind } \\
\text { speed }(\mathrm{m} / \mathrm{s})\end{array}$ & $\begin{array}{c}\text { Prevailing } \\
\text { wind } \\
\text { direction }\end{array}$ & $\begin{array}{c}\text { Number of rainy } \\
\text { days }\end{array}$ \\
\hline Rainy season & 30.0 & 74.9 & 2.7 & SSE & $2 / 17$ sampling days \\
\hline Dry season & 24.7 & 77.8 & 2.8 & $\mathrm{E}$ & $8 / 28$ sampling days \\
\hline
\end{tabular}

Quartz fiber filters were pre-baked at $900{ }^{\circ} \mathrm{C}$ for four hours to remove possible contamination [12]. To determine the mass of NPs, the filters were weighed on an electronic micro-balance, Sartorius ME2, $10^{-6} \mathrm{~g}$, before and after field sampling. Prior to being weighed, the filters were equilibrated in the balance room for at least 24 hours. The balance room's relative humidity was maintained at a mean value range of $30-40 \%$ and the temperature was kept from $20-23{ }^{\circ} \mathrm{C}$ [13]. After weighing, each quartz filter was put in a Petri dish and kept in a separate airtight bag. The samples were frozen at Ha Noi University of Science and Technology and were transported in a dry ice box to the Saitama University's laboratory in Japan for OC/EC, WSOC analyses.

A quarter of each sample filter was extracted with $10 \mathrm{~mL}$ pure water for WSOC analyses. After the samples were ultrasonically extracted, they were filtered (pore size, $0.2 \mu \mathrm{gm}$ ) and the solute was injected to total carbon analyzer $\left(\mathrm{TOC}-\mathrm{V}_{\mathrm{CHP}}\right.$, Shimazu Corp., Japan) to determine the concentration of WSOC. 
A $0.503 \mathrm{~cm}^{2}$ sample punched out from the quartz fiber filter was used to determine OC and EC using a thermal/optical carbon analyzer (DRI model 2001, Atmoslytic Inc, Calabasas, CA, USA). Temperature was set up with the IMPROVE method with four OC fractions (OC1, OC2, OC3, OC4 at 120, 250, 450, and $550{ }^{\circ} \mathrm{C}$, respectively in a non-oxidizing helium atmosphere) and three EC fractions (EC1, EC2, and EC3 at 550, 700, and $800{ }^{\circ} \mathrm{C}$, respectively in an oxidizing helium atmosphere of $2 \% \mathrm{O}_{2}$ and $98 \%$ of helium). The pyrolysis of OC (POC) was continuously monitored by reflectance or transmittance of laser signal. OC is operationally defined as $\mathrm{OC} 1+\mathrm{OC} 2+\mathrm{OC} 3+\mathrm{OC} 4+\mathrm{POC}$, and $\mathrm{EC}$ is defined as $\mathrm{EC} 1+\mathrm{EC} 2+\mathrm{EC} 3-\mathrm{POC}$. The EC fraction was divided into char-EC and soot-EC [14-15]. Char-EC is defined as EC1 minus POC, and the soot-EC is defined as the sum of EC2 and EC3 [16].

An electrical mobility spectrometer (NanoScan, SMPS TSI Model 3910; sample flow rate $0.6 \mathrm{~L} \mathrm{~min}^{-1}$ ) was utilized to measure the particle mobility size distribution in 13 channels from 10 to $420 \mathrm{~nm}$ mobility diameter. Time resolution was 1 minute. During each season, 30 samples were conducted. The spectrometers generally include an electrostatic classifier, where particles are electrically charged/neutralized and then classified according to their electrical mobility and a condensation particle counter, where particles, previously classified, are counted.

\section{RESULTS AND DISCUSSIONS}

\subsection{Levels of $\mathbf{P M}_{0.1}$ and WSOC}

\section{Mass concentrations}

The mean concentrations of mass, carbonaceous species (EC, OC, and WSOC) are summarized in Table 2, together with the median, minimum and maximum concentrations of the chemical species.

Generally, mass and WSOC concentrations of NPs in the rainy season were slightly higher than those in the dry season. The average mass concentrations of nanoparticles in the rainy season and the dry season were $5.42 \pm 2.24 \mu \mathrm{g} / \mathrm{m}^{3}$ and $4.76 \pm 1.67 \mu \mathrm{g} / \mathrm{m}^{3}$ respectively, while the WSOC concentrations of those were $1.51 \pm 0.31 \mu \mathrm{g} / \mathrm{m}^{3}$ and $1.09 \pm 0.29 \mu \mathrm{g} / \mathrm{m}^{3}$. These results might be explained by the different number of rainy days in the two sampling periods as shown in Table 1.

Table 2. Average mass and carbonaceous concentrations.

\begin{tabular}{|c|c|c|c|c|c|c|}
\hline & \multicolumn{3}{|c|}{$\begin{array}{c}\text { Rainy season }\left(4^{\text {th }}-20^{\text {th }} \text { Aug. } 2015\right), \\
n=17 \text { samples, } \mu \mathrm{g} / \mathrm{m}^{3}\end{array}$} & \multicolumn{3}{|c|}{$\begin{array}{c}\text { Dry season }\left(4^{\text {th }} \text { Nov }-1^{\text {st }} \text { Dec. } 2015\right) \\
n=28 \text { samples, } \mu \mathrm{g} / \mathrm{m}^{3}\end{array}$} \\
\hline & Mean & Median & Range & Mean & Median & Range \\
\hline Mass & 5.42 & 4.99 & $2.38-11.8$ & 4.76 & 4.30 & $1.85-9.13$ \\
\hline WSOC & 1.51 & 1.57 & $0.90-2.11$ & 1.09 & 1.06 & $0.51-1.83$ \\
\hline WSOC/OC & 0.66 & 0.69 & $0.24-0.97$ & 0.59 & 0.62 & $0.28-0.76$ \\
\hline WIOC & 1.06 & 0.61 & $0.05-4.57$ & 0.76 & 0.71 & $0.36-2.14$ \\
\hline WIOC/OC & 0.34 & 0.31 & $0.03-0.76$ & 0.41 & 0.38 & $0.26-0.72$ \\
\hline
\end{tabular}

(WIOC: water in-soluble organic carbon, WIOC $=$ OC - WSOC).

The nanoparticle concentrations obtained are compared with those of others studies as shown in Table 3. Disparities of nanoparticle concentrations support the likelihood of sitespecific differences such as sampling period and location. It may be needed to know the 
concentrations of nanoparticles at different time periods under various environmental conditions to get a better understanding about the level of nanoparticles in the atmosphere. However, the mass concentrations of NPs in Viet Nam were roughly from 2 to 10 times higher than those in other urban sectors. To answer the questions such as what are the main sources that make the contribution to the higher concentration of NPs in Viet Nam, what are the effects of these higher concentrations on human health and environment, the further studies of NPs in Viet Nam are needed to investigate.

Table 3. Concentrations of NPs at different locations.

\begin{tabular}{lccc}
\hline \multicolumn{1}{c}{ Studies } & Location & Site feature & Concentration $\left(\boldsymbol{\mu g} / \mathbf{m}^{\mathbf{3})}\right.$ \\
\hline This study & HUST, Ha Noi & Mixed & $4.76-5.42$ \\
\hline Thuy et al. [8] & Gia Lam, Ha Noi & Traffic & $6.40-9.70$ \\
\hline Cass et al. (2000) [3] & California, US & Urban - industrial & $0.60-1.20$ \\
\hline Gugamsetty (2012) [17] & Taiwan & Urban - industrial & $1.40 \pm 0.60$ \\
\hline Pakkanen et al. (2001) [18] & Finland & Rural & 0.52 \\
\hline Pakkanen et al. (2001) [18] & Finland & Urban & 0.49 \\
\hline Mbengue et al. (2014) [19] & Dunkrink, France & Industrial & 0.80 \\
\hline Mbengue et al. $(2014)$ [19] & Dunkrink, France & Urban - industrial & 0.50 \\
\hline Chen et al. (2010) [4] & Hsinchu, Taiwan & Traffic & $2.21 \pm 0.59$ \\
\hline Chen et al. (2010) [4] & Hsinchu, Taiwan & Forest & $0.65 \pm 0.31$ \\
\hline Chen et al. (2010) [4] & Hsinchu, Taiwan & Tunnel & $33.2 \pm 6.5$ \\
\hline Kim et al. (2002) [20] & Los Angeles, US & Riverside & 1.34 \\
\hline Kim et al (2002) [20] & Los Angeles, US & Urban & 4.11 \\
\hline
\end{tabular}

\section{Number concentrations}

The mass concentrations of the particles smaller than $100 \mathrm{~nm}$, which actually dominate the total particle number concentrations in urban areas, are negligible. Therefore, accompany with mass concentration, number concentrations and size distributions are often measured when studying NPs. Figure 2 shows the distribution of average particle sizes measured at the sampling site.

The average particle number concentrations of the nucleation mode $(3-20 \mathrm{~nm})$, Aitken mode $(20-100 \mathrm{~nm})$, and accumulation mode $(>100 \mathrm{~nm})$ are 3,836 particles $/ \mathrm{cm}^{3}, 27,340$ particles $/ \mathrm{cm}^{3}$, and 3,885 particles $/ \mathrm{cm}^{3}$, respectively. The particle number concentration of the Aitken mode is obviously higher than those of the other modes. Since the majority of particle number from vehicle exhaust is in the size range of $20-130 \mathrm{~nm}$ for diesel engines and 20-60 $\mathrm{nm}$ for gasoline engines [21-23], the very high number concentration in Aiken mode (71\%) indicates the influence of traffic emissions in the study area.

The average number concentrations in this study were compared with others conducted in different conditions (Figure 3). Overall, 43 roadside sites, 6 urban sites, and 2 urban background studies were calculated to get the mean values of each site [4, 21 - 24] The average concentration of particles below $100 \mathrm{~nm}$ (with an average value of 31,117 particles $/ \mathrm{cm}^{3}$ ) in HUST is about 2.6 times higher than those in the urban background sites, and was close to those in the urban sites. The mean value of number concentrations of NPs in this study is lower than that of roadside sites. However, the number concentrations in reference studies had a huge range (from 8,020 to 600,000 particles $/ \mathrm{cm}^{3}$ ), in which the values from 20,000 to 40,000 particles $/ \mathrm{cm}^{3}$ reached to $48.83 \%$ (21/43 values). One reason might be that these studies were conducted with 
different distances from the road kerb, different duration, and different samplers. Therefore, results obtained in this study can be considered in the same range with those of other studies in the urban and roadside environment.

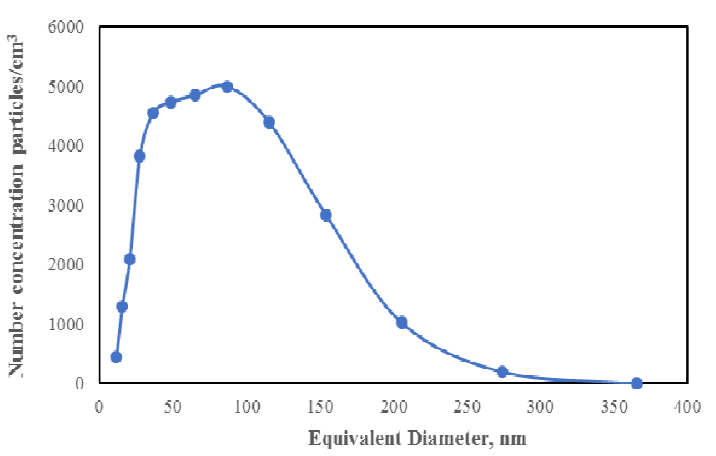

Figure 2. Distribution of number concentration of NPs.

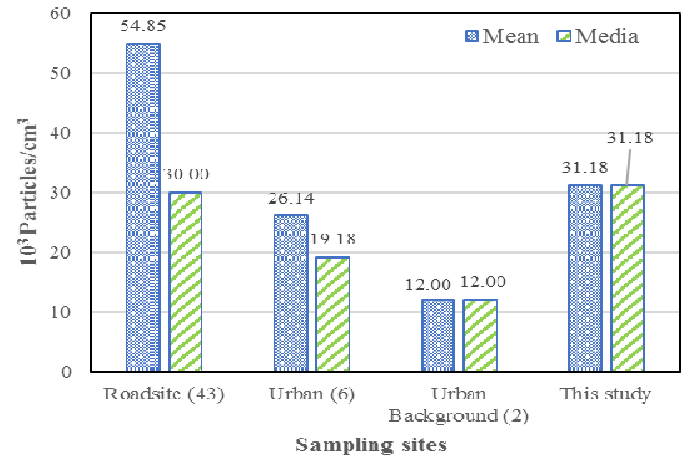

Figure 3. Mean and median particle number concentrations for different environments.

\subsection{Relationships between WSOC and carbonaceous components}

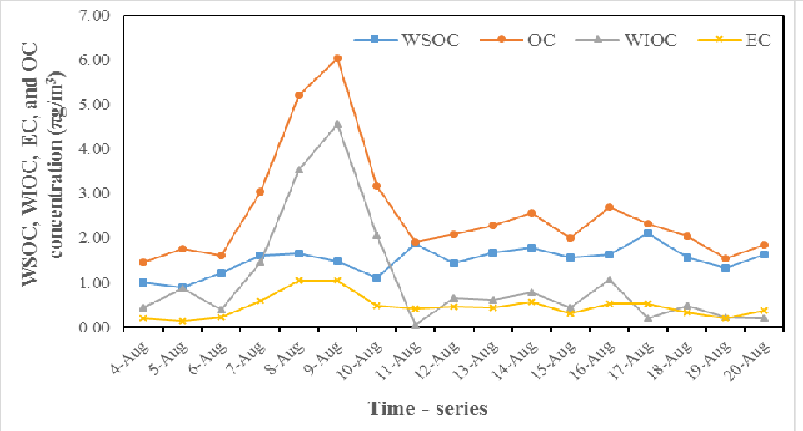

Rainy season

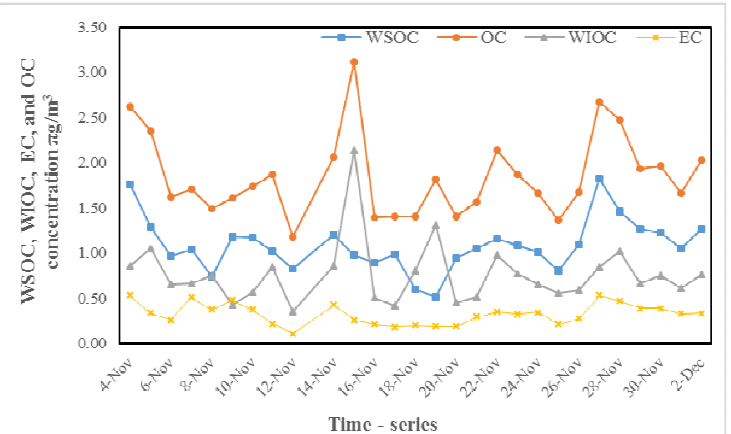

Dry season

Figure 4. Temporal variations of WSOC, WIOC, EC, and OC in the rainy and dry season.

WSOC can account for 40 to $80 \%$ of the total organic carbon, depending on the location and season [5, 6, 16, 25]. As shown in Table 2 and Figure 4, the WSOC concentrations in aerosols in this study ranged from 0.90 to $2.11 \mu \mathrm{g} / \mathrm{m}^{3}$ (Av: $1.51 \mu \mathrm{g} / \mathrm{m}^{3}$ ) in the rainy season and 0.51 to $1.83 \mu \mathrm{g} / \mathrm{m}^{3}$ (Av: $\left.1.09 \mu \mathrm{g} / \mathrm{m}^{3}\right)$ in the dry season, i.e. 1.4 times higher in rainy season. The WSOC abundance contributes $66.5 \%$ and $58.7 \%$ of OC in the rainy season and the dry season, respectively. The concentrations of WSOC in the rainy season were higher than those in the dry season. The relatively low WSOC concentrations observed in the dry season might be due to the abnormal rainfall during this sampling period. The mass and carbonaceous concentrations of particles were also relatively low in this season, and that decline might also be due to anomalous rain showers.

The WSOC/OC ratios ranged from $0.59 \mu \mathrm{g} / \mathrm{m}^{3}$ to $0.66 \mu \mathrm{g} / \mathrm{m}^{3}$ while the WIOC/EC ratios were around $2.30 \mu \mathrm{g} / \mathrm{m}^{3}$. Typically, both WSOC and WIOC concentrations in this study are two times higher than those of other studies; whereas the WSOC/OC and ratios can be considered to be stable at all locations as shown in Table 4. 
Table 4. WSOC, WIOC and their ratios with carbonaceous concentrations of NPs of different locations.

\begin{tabular}{lccccc}
\hline \multicolumn{1}{c}{ Site } & Sampling location & WSOC & WIOC & WSOC/OC & WIOC/EC \\
\hline This study & Ha Noi (mixed site) & $1.09-1.51$ & $0.76-1.06$ & $0.59-0.66$ & 2.30 \\
\hline Japan [16] & Saitama (roadside) & $0.45-0.60$ & $0.40-0.59$ & $0.47-0.62$ & $2.74-4.00$ \\
\hline Germany [14] & Berlin (roadside) & 0.54 & 0.59 & 0.50 & 4.6 \\
\hline US [15] & New York (rural area) & 0.66 & N/A & N/A & N/A \\
\hline
\end{tabular}

WSOC and WIOC concentrations showed significant site-to-site variability that indicates the influence of local primary sources of WSOC, such as biomass burning, or differences in the emissions of precursors to the secondary organic aerosol formation. However, the consistent WSOC/OC ratios can be found corresponding to a certain location and season.

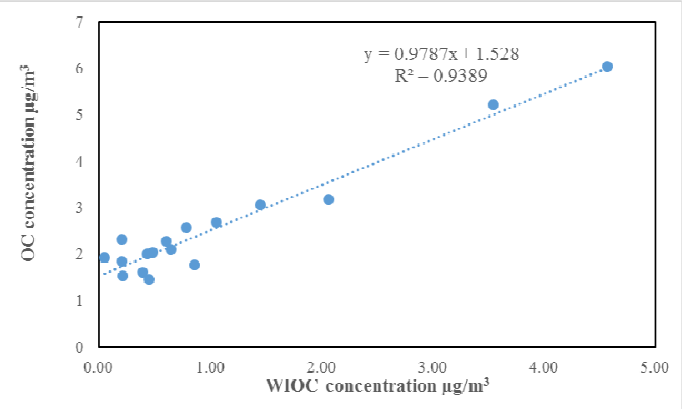

a) Correlations of WIOC with OC

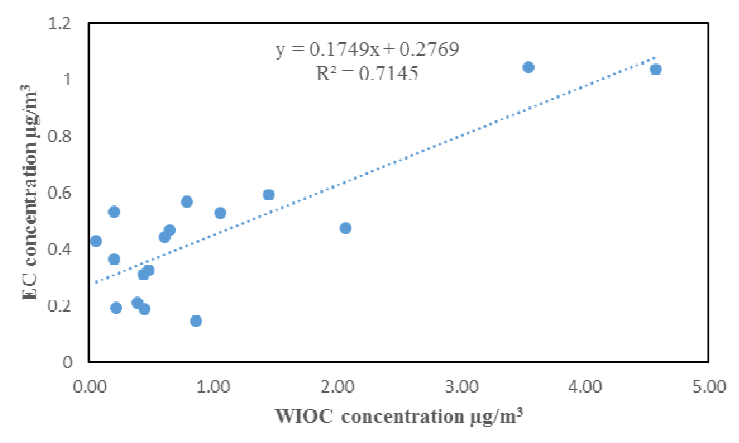

b) Correlations of WIOC and EC

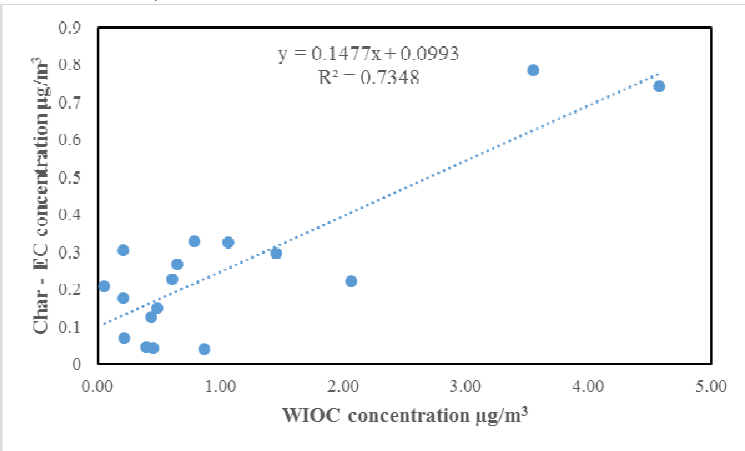

c) Correlations of WIOC with char-EC

Figure 5. Correlations of WIOC with OC, EC, and char-EC in the rainy season.

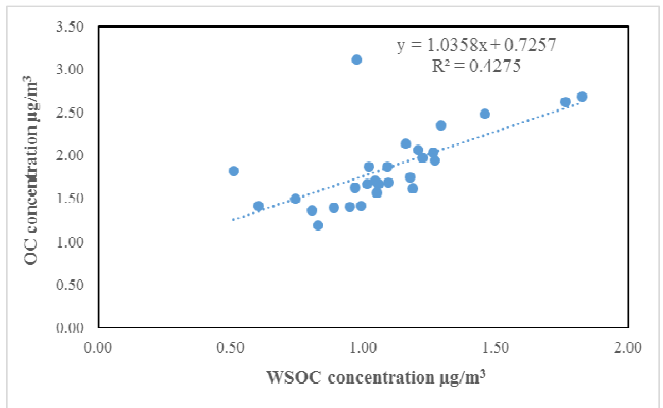

a) Correlations of WSOC and OC

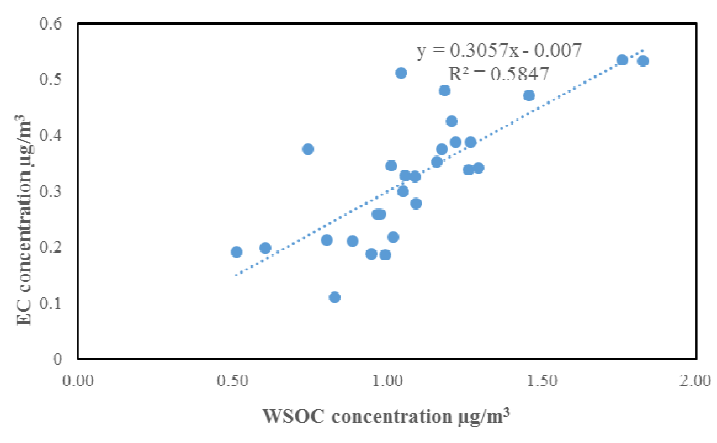

b) Correlations of WIOC and EC

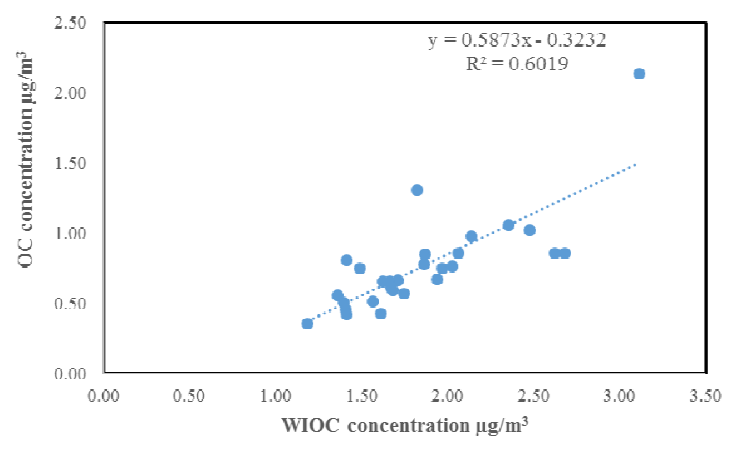

c) Correlations of WIOC and OC

Figure 6. Correlations of WSOC with OC and EC; WIOC and OC in the dry season. 
In order to primarily identify the sources of NPs, the deeper relationships between WSOC, WIOC, OC, EC, char - EC, and soot - EC were investigated. While EC originates from the burning of carbonaceous matter, OC may be emitted directly in the particulate phase or formed from a gas-to-particle conversion process in the atmosphere [26]. WSOC can be produced from both primary and secondary emissions, most of WIOC in urban areas were likely formed via incomplete combustion of fossil fuels [27]. Char - EC is formed when carbonaceous material is partially burned or heated with a limited supply of air; whereas, soot - EC was formed at high temperature via gaseous phase processes [28]. Therefore, analysis the relationships between them will help us have useful indicators for source identification.

The significant positive correlations between WIOC with OC, EC, and char - EC as shown in Figure 5a, Figure 5b, and Figure 5c, respectively for the rainy season indicates that the main sources of OC were primary OC; whereas the found correlations between WSOC with OC, and $\mathrm{EC}$, and between WIOC with $\mathrm{OC}$ as presented in Figure 6a, Figure 6b, and Figure 6c, respectively for the dry season shows the higher contribution of secondary emission in this season.

\subsection{Estimation of secondary $\mathrm{OC}$ concentration}

OC can be either emitted directly by primary sources (primary OC) or formed by condensation of low-volatility products from the photochemical oxidation of gaseous organic precursors [29]. To establish a control strategy for particulate matter pollution, the contributions of primary and secondary OC to the total OC needs to be estimated.

The SOA fraction in aerosol is either estimated using the EC - tracer method [30] or by adding up all the oxidation products found in aerosols [25]. In this study, EC - tracer method was used to estimate the contribution of SOA to the measured OC. This technique has been used to distinguish primary $\mathrm{OC}$ from secondary $\mathrm{OC}$ in numerous studies. The underlying hypothesis is that because EC and primary OC often have the same sources, there is a representative ratio of primary $\mathrm{OC} / \mathrm{EC}$ for a given area (hereafter referred to as $[\mathrm{OC} / \mathrm{EC}]_{\mathrm{pri}}$ ). Herein, the primary organic carbon concentrations, $[\mathrm{OC}]_{\mathrm{pri}}$, were estimated as follows:

$$
[\mathrm{OC}]_{\mathrm{pri}}=[\mathrm{OC} / \mathrm{EC}]_{\mathrm{pri}}[\mathrm{EC}]+[\mathrm{OC}]_{\mathrm{NC}}
$$

where $[\mathrm{OC}]_{\text {pri }}$ is the primary organic aerosol concentration, $[\mathrm{OC} / \mathrm{EC}]_{\text {pri }}$ is the ratio of $\mathrm{OC}$ to $\mathrm{EC}$ for the primary sources, and $[\mathrm{OC}]_{\mathrm{NC}}$ is the non-combustion contribution to the primary OC. Then, the secondary organic carbon (SOA) concentration, [OC]sec, is simply the difference between the measured total $[\mathrm{OC}],[\mathrm{OC}]_{\mathrm{tot}}$, and the estimated primary $[\mathrm{OC}]_{\text {pri }}$.

$$
[\mathrm{OC}]_{\mathrm{sec}}=[\mathrm{OC}]_{\mathrm{tot}}-[\mathrm{OC}]_{\mathrm{pri}}
$$

Numerous methods for determining the value of $[\mathrm{OC} / \mathrm{EC}]_{\mathrm{pri}}$ and $[\mathrm{OC}]_{\mathrm{NC}}$ have been used in previous studies. Castro et al. (1999) reported that the consistent presence of a clear minimum ratio for $\mathrm{OC} / \mathrm{EC}$ in urban and rural areas, in winter and summer, suggests that samples having the lowest OC/EC ratios contain almost exclusively primary carbonaceous compounds [31]. For this work, we assumed that the values of 4.45 and 3.35 for $(\mathrm{OC} / \mathrm{EC})_{\min }$ observed in the rainy and dry season, respectively were used as $[\mathrm{OC}]_{\text {pri }}$ and the concentration of primary non-combustion contribution was negligible. If primary non-combustion OC had contributed to the observed OC, the estimated secondary OC concentration would be overestimated. Based on this approach, SOA was been estimated about $0.56 \mu \mathrm{g} / \mathrm{m}^{3}$ and $0.76 \mu \mathrm{g} / \mathrm{m}^{3}$ in the rainy and dry season, respectively, accounting for $21.67 \%$ and $41.20 \%$ of the measured OC. These results showed good correlations with the primary prediction of sources as presented in Section 3.2. 


\section{CONCLUSIONS}

This study was designed to contribute to initiate the researches of nanoparticles in Viet Nam. Mass concentrations, number concentration and WSOC of NPs at a mixed site of Ha Noi in the rainy season and the dry season were determined. The mass concentrations of nanoparticles were $4.76 \mu \mathrm{g} / \mathrm{m}^{3}$ to $5.42 \mu \mathrm{g} / \mathrm{m}^{3}$ while the number concentrations of these particles were $2.59 \times 10^{4}-3.54 \times 10^{4}$ particles $/ \mathrm{cm}^{3}$. The average concentrations of WSOC in the rainy and dry season were $1.51 \mu \mathrm{g} / \mathrm{m}^{3}$ and $1.09 \mu \mathrm{g} / \mathrm{m}^{3}$, respectively. The relationship between WSOC and other components, particularly WIOC, OC, EC, char - EC, soot - EC were used to primarily identify the sources of emission. The good positive correlations of WIOC with OC, EC, and char - $\mathrm{EC}$ (with $\mathrm{R}^{2}=0.94,0.71,0.73$, respectively) in the rainy season; and the moderate correlations of WSOC with OC and EC $\left(\mathrm{R}^{2}=0.43,0.58\right.$, respectively), and of WIOC with OC $\left(\mathrm{R}^{2}=0.60\right)$ in the dry season were found. From these findings, a higher SOA was anticipated in the dry season. These results showed the good agreement with the EC - tracer method, in which SOA was accounted for $21.67 \%$ and $41.20 \%$ in the rainy and dry season, respectively.

Acknowledgments. Kanazawa University, Japan is acknowledged for providing the sampler (KU - TSC 26A57C1) for this study.

\section{REFERENCES}

1. Wichmann H. E., Spix C., Tuch T., Wölke G., Peters A., Heinrich J., Kreyling W. G., Heyder J. - Daily mortality and fine and ultrafine particles in Erfurt, Germany part I: role of particle number and particle mass, Research report 98 (2000) 5-86.

2. Anastasio, C. \& Martin, S.T. - Atmospheric nanoparticles, In: Nanoparticles and the Environment, Mineralogical Society of America (2001) 293-349.

3. Salmon G. R. Cass; L. A. Hughes; P. Bhave; M. J. Kleeman; J. O. Allen; L. G. - The chemical composition of atmospheric ultrafine particles, Philosophical Transactions Mathematical Physical \& Engineering Sciences 358 (1775) (2000) 2581 - 2592.

4. Sheng-Chieh Chen, Chuen-Jinn Tsai, Charles C.-K. Chou, Gwo-Dong Roam, Sen-Sung Cheng, Ya-Nan Wang - Ultrafine particles at three different sampling locations in Taiwan, Atmospheric Environment 44 (4) (2010) 533 - 540.

5. Kimiyo Kumagaia, Akihiro Iijima, Hiroshi Tagoa, Atsushi Tomiokaa, Kunihisa Kozawaa, Kazuhiko Sakamoto - Seasonal characteristics of water-soluble organic carbon in atmospheric particles in the inland Kanto plain, Japan. Atmospheric Environment $\mathbf{4 3}$ (2009) 3345-3351.

6. Herner JD, Aw J, Gao O, Chang DP, Kleeman MJ. - Size and Composition Distribution of Airborne Particulate Matter in Northern California 1. Particulate Mass, Carbon, and Water-Soluble Ions, Journal of the Air \& Waste Management Association 55 (1) (2005) $30-51$.

7. Vishal Verma, Roberto Rico-Martinez, Neel Kotra, Laura King, Jiumeng Liu, Terry W. Snell, Rodney J. Weber - Contribution of water-soluble and insoluble components and their hydrophobic/hydrophilic subfractions to the reactive oxygen species-generating potential of fine ambient aerosols, Environmental Science \& Technology 46 (2012) 11384-11392. 
8. Nguyen Thi Thu Thuy, Nghiem Trung Dung, Kazuhiko Sekiguchi, Ryosuke Yamaguchi, Pham Chau Thuy, Duong Thanh Nam, Ho Quoc Bang, Thai Thuy An - Seasonal Variation of Concentrations and Carbonaceous Components of Nanoparticles at a Roadside Location of Ha Noi, Viet Nam, Procedings of International Conference on Environmental Engineering and Management for Sustainable Development, Bach Khoa Publishing house, September (2016) 81-86

9. Ryosuke Yamaguchi, Kazuhiko Sekiguchi1, Kenshi Sankoda, Hirotoshi Kuwabara, Kimiyo Kumagai, Yuji Fujitani, Nguyen Thi Thu Thuy, Nghiem Trung Dung, Seasonal variation of chemical components in $\mathrm{PM}_{2.5}$ and $\mathrm{PM}_{0.1}$ in Ha Noi, Procedings of International Conference on Environmental Engineering and Management for Sustainable Development, Bach Khoa Publishing house, September 2016, pp. 75-80.

10. Nguyen Thi Thu Thuy, Nghiem Trung Dung, Kazuhiko Sekiguchi, Ryosuke Yamaguchi, Pham Chau Thuy, Ho Quoc Bang - Characteristics of Elemental Carbon and Organic Carbon in Atmospheric Nanoparticles at Different Sampling Locations in Viet Nam, Vietnam Journal of Science and Technology 55 (3) (2017) 305-315 .

11. Hien, P.D., Bac, V.T., Tham, H.C., Nhan, D.D., Vinh, L.D. - Influence of meteorological conditions on $\mathrm{PM}_{2.5}$ and $\mathrm{PM}_{2.5-10}$ concentrations during the monsoon season in $\mathrm{Ha}$ Noi, Viet Nam, Atmospheric Environment 36 (21) (2002) 3473-3484.

12. Desert Research Institute, Division of Atmospheric Sciences, DRI STANDARD OPERATING PROCEDURE, DRI Model 2001 Thermal/Optical Carbon Analysis (TOR/TOT) of Aerosol Filter Samples, DRI SOP \#2-216.1, Revised November 2005.

13. Chow, J.C., Watson, J.G., Crow, D., Lowenthal, D.H., Merrifield, T. - Comparison of IMPROVE and NIOSH carbon measurements. Aerosol Science and Technology 34 (2001) 23-34.

14. Shinji Kudo, Kazuhiko Sekiguchi, Kyung Hwan Kim, Masatoshi Kinoshita, Qingyue Wang, Hiroshi Yoshikado, Kazuhiko Sakamoto, Detlev Möller - Differences of chemical species and their ratios between fine and ultrafine particles in the roadside environment, Atmospheric Environment 62 (2012) 172-179.

15. Pavlovic J., Hopke P.K. - Chemical nature and molecular weight distribution of the watersoluble fine and ultrafine PM fractions collected in a rural environment, Atmospheric Environment 59 (2012) 264-271.

16. Kyung Hwan Kim, Kazuhiko Sekiguchi, Masami Furuuchi, Kazuhiko Sakamoto Seasonal variation of carbonaceous and ionic components in ultrafine and fine particles in an urban area of Japan, Atmospheric Environment 45 (2011) 1581- 1590.

17. Balakrishnaiah Gugamsetty, Han Wei, Chun-Nan Liu, Amit Awasthi, Shih-Chieh Hsu, Chuen-Jinn Tsai, Gwo-Dong Roam, Yue-Chuen Wu, Chung-Fang Chen - Source characterization and apportionment of $\mathrm{PM}_{10}, \mathrm{PM}_{2.5}$ and $\mathrm{PM}_{0.1}$ by using positive matrix factorization, Aerosol and Air Quality Research 12 (2012) 476-491.

18. Tuomo A Pakkanen, Veli-Matti Kerminen, Christina H Korhonen, Risto E Hillamo, Päivi Aarnio, Tarja Koskentalo, Willy Maenhaut - Urban and Rural Ultrafine (PM0.1) Particles in the Helsinki Area, Atmospheric Environment 35 (27) (2001) 4593-4607.

19. Saliou Mbengue, Laurent Y. Alleman, Pascal Flament - Size-distributed metallic elements in submicronic and ultrafine atmospheric particles from urban and industrial areas in northern France, Atmospheric Research 135-136 (2014) 35-47. 
20. Kim S., Shen, S., Sioutas, C., Zhu, Y. and Hinds, W. C. - Size Distribution and Diurnal and Seasonal Trends of Ultrafine Particles in Source and Receptor Sites of the Los Angeles Basin, Journal of the Air \& Waste Management Association 53 (2002) 297 - 307.

21. Yifang Zhu, William C. Hinds, Seongheon Kim, Si Shen, Constantinos Sioutas - Study of ultrafine particles near a major highway with heavy-duty diesel traffic, Atmospheric Environment 36 (2002) 4323-4335.

22. Morawska, L., Ristovski, Z., Jayaratne, E.R., Keogh, D.U. \& Ling, X. - Ambient nano and ultrafine particles from motor vehicle emissions: characteristics, ambient processing and implications on human exposure, Atmospheric Environment 42 (35) (2008) 81138138.

23. Zhijun Wu, Min Hu, Peng Lin,, Shang Liu, Birgit Wehner, Alfred Wiedensohler - Particle number size distribution in the urban atmosphere of Beijing, China, Atmospheric Environment 42 (34) (2008) 7967-7980.

24. Prashant Kumar, L.M., Wolfram Birmili, Pauli Paasonen, Min Hu, Markku Kulmala, Roy M. Harrison, Leslie Norford, Rex Britter - Ultrafine particles in cities, Environment International 66 (2014) 1-10.

25. Kirpa Ram, M.M. Sarin - Spatio-temporal variability in atmospheric abundances of EC, OC and WSOC over Northern India, Journal of Aerosol Science 41 (2010) 88-98.

26. Jones, A.M., Harrison, R.M - Interpretation of particulate elemental and organic carbon concentrations at rural, urban and kerbside sites. Atmospheric Environment 39 (2005) 71147126.

27. Bernd RT Simoneit, M.K., Michihiro Mochida, Kimitaka Kawamura, Meehye Lee, Ho-Jin Lim, Barbara J Turpin, Yuichi Komazaki - Composition and major sources of organic compounds of aerosol particulate matter sampled during the ACE-Asia campaign, Journal of Geophysical Research: Atmospheres 109 (2004) D19.

28. Lim S., Lee M., Lee G., Kim S., Yoon S. and Kang K. - Ionic and carbonaceous compositions of $\mathrm{PM}_{10}, \mathrm{PM}_{2.5}$ and $\mathrm{PM}_{1.0}$ at Gosan $\mathrm{ABC}$ Superstation and their ratios as source signature, Atmospheric Chemistry and Physics 12 (2012) 2007-2012.

29. Seinfeld, J.H., Pandis, S.N. - Atmospheric Chemistry and Physics: from Air Pollution to Climate Change. John Wiley and Sons, New York, 1998, pp. 18-21, 507-519 and 11131192.

30. Turpin, B.J., Huntzicker, J.J. - Identification of secondary organic aerosol episodes and quantification of primary and secondary organic aerosol concentrations during SCAQS, Atmospheric Environment 99 (1995) 3527-3544.

31. Castro, L.M., Pio, C.A., Harrison, R.M., Smith, D.J.T. - Carbonaceous aerosol in urban and rural European atmospheres: estimation of secondary organic carbon concentrations, Atmospheric Environment 33 (1999) 2771-2781. 